\title{
Analysis of VEGF polymorphisms, tumor expression of VEGF mRNA and colorectal cancer susceptibility in a Swedish population
}

\author{
JONAS UNGERBÄCK ${ }^{1}$, NILS ELANDER ${ }^{1}$, JAN DIMBERG $^{2}$ and PETER SÖDERKVIST ${ }^{1}$ \\ ${ }^{1}$ Department of Clinical and Experimental Medicine, Division of Cell Biology, Faculty of Health Sciences, \\ Linköping University, SE-581 85 Linköping; ${ }^{2}$ Department of Natural Science and Biomedicine, \\ University College of Health Sciences, SE-551 11 Jönköping, Sweden
}

Received October 21, 2008; Accepted December 10, 2008

DOI: $10.3892 / \mathrm{mmr} 00000118$

\begin{abstract}
Vascular endothelial growth factor (VEGF) plays a significant role in tumor angiogenesis and is found to be overexpressed and involved in the development and progression of colorectal cancer (CRC). The VEGF gene contains several polymorphic sites known to influence VEGF expres-sion. We examined the possible association between five polymorphisms, located in the promoter $/ 5$ '-untranslated region [-2578 (C/A), -2549 (del/ins 18 bp), -1154 (G/A), -634 (G/C)] or 3'-untranslated region $[+936(\mathrm{C} / \mathrm{T})]$ of the VEGF gene, and CRC susceptibility and clinicopathological characteristics in 302 Swedish CRC patients and 336 healthy randomly selected controls. Both genotypes and combined haplotypes were analyzed. No significant differences were observed when VEGF genotype/haplotype frequencies in the CRC cases and controls were compared, nor were any associations found between the genotypes/haplotypes and clinicopathological characteristics. However, when the $-2578 \mathrm{C}$ and $+936 \mathrm{~T}$ alleles were combined, a small but significant association with CRC susceptibility was detected $(\mathrm{OR}=1.6,95 \% \mathrm{CI} 1.3-1.9, \mathrm{p}=0.01)$. In addition, VEGF mRNA expression was determined in a subset of patients, revealing a 2-fold VEGF upregulation in CRC tissue compared to normal colonic mucosa, but no association between the genotypes or haplotypes and VEGF mRNA levels. Linkage analysis was performed, revealing that the polymorphisms in the promoter and 5'-untranslated region were in tight linkage disequilibrium (LD) (ID'l=0.91-1.00), while the $+936 \mathrm{C} / \mathrm{T}$ polymorphism was only weakly associated with the others $\left(\left|D^{\prime}\right|=0.05-0.19\right)$. In conclusion, VEGF is generally upregulated in colorectal tumors. However, the
\end{abstract}

Correspondence to: Dr Jonas Ungerbäck, Department of Clinical and Experimental Medicine, Division of Cell Biology, Faculty of Health Sciences, Linköping University, SE-581 85 Linköping, Sweden

E-mail: jonun@ibk.liu.se

Key words: vascular endothelial growth factor, colorectal cancer, mRNA, single nucleotide polymorphism, haplotype analysis single nucleotide polymorphisms examined do not appear to influence the mRNA expression of VEGF in colorectal tumors, and most likely play a limited role in CRC development and progression.

\section{Introduction}

The vascular endothelial growth factor (VEGF) is one of the most important initiators and regulators of angiogenesis and a key factor in cancer growth and progression (1).

The VEGF gene is located on chromosome 6p12 and includes a 14-kb coding region, consisting of eight exons and exhibiting alternate splicing to form a family of proteins (2). The gene is highly polymorphic, and several single nucleotide polymorphisms (SNPs) have been associated with altered gene expression and higher VEGF plasma levels (3-7). In addition, previous studies have revealed a correlation with cancer development and progression (8-11), as well as with Behcet's disease, adult respiratory distress syndrome, rheumatoid arthritis and psoriatic arthritis (12-15).

Colorectal cancer (CRC) is one of the most common malignancies in the world, with approximately 1 million new cases and half a million deaths worldwide in 2002 (16). VEGF has also been demonstrated to be overexpressed in CRC tissue compared to normal colonic mucosa (17-20). Therefore, antiangiogenic therapy with VEGF inhibitors has attracted much attention as an additional treatment to standard therapeutic strategies for cancer. However, no predictive markers for high VEGF levels exist at present (21).

In the present study, five polymorphisms of the VEGF gene and their possible association with VEGF mRNA levels, CRC development and various additional clinical/ pathological characteristics were investigated in Swedish CRC patients. Three of the polymorphisms are located in the promoter region at positions $-2578,-2549$ and -1154 ; one is in the 5 '-untranslated region at position -634 , and the fifth in the 3 '-untranslated region at position +936 (7).

In brief, VEGF mRNA was found to be overexpressed in CRC tissue compared to adjacent normal colonic mucosa, while no or only weak associations were evident between the SNPs examined in the VEGF gene, VEGF mRNA tumor levels and the risk of developing CRC. 


\section{Materials and methods}

Patients and DNA isolation. Normal blood samples and/or normal intestinal tissue from $302 \mathrm{CRC}$ patients were collected at the County Hospital Ryhov, Jönköping and University Hospital, Linköping, Sweden, and were immediately snapfrozen and stored at $-70^{\circ} \mathrm{C}$ until DNA isolation. Clinical information was obtained for the majority of the patients, including age and gender, Dukes' staging, polypoid/ulcerative phenotype and survival data (data not shown). Three hundred and thirty-six blood samples, randomly collected but agematched with the CRC group, were used as controls. Samples were from a Swedish normal healthy population from the same geographical region as the CRC patients.

Genomic DNA was isolated from the tissue and normal blood samples with the Wizard ${ }^{\circledR}$ Genomic DNA Purification Kit according to the supplier's recommendations (Promega, Madison, WI, USA).

The study was approved by the Research Ethics Committee at the Faculty of Health Sciences, Linköping, Sweden (Dnr. 98113).

Quantitative RT-PCR. Total RNA was isolated from 33 colorectal tumors and 22 corresponding normal colonic mucosa according to Dimberg et al (22).

RNA (200 ng) from each sample was reversely transcribed into cDNA with SuperScript ${ }^{\mathrm{TM}}$ III (Invitrogen) according to the supplier's recommendations. The relative gene expression of VEGF and of the internal control gene $\beta$-glucuronidase (GUSB) was determined by real-time PCR (7500 Fast RealTime PCR System, Applied Biosystems, Foster City, CA, USA), performed with the TaqMan ${ }^{\circledR}$ Fast Universal PCR Master Mix (Applied Biosystems) and predesigned primer/ probe mixes for VEGF (Hs00900054_m1, Applied Biosystems) and GUSB (4333767T, Applied Biosystems), respectively. Samples were run in duplicate, and the mean $\mathrm{Ct}$ values were translated into a relative concentration unit presented by the standard curve, which was co-amplified in each experiment. Finally, relative concentrations of VEGF were normalized to the expression of GUSB. VEGF levels in the tumor group and the normal colonic mucosa were compared, and their association with different VEGF genotypes and haplotypes was explored.

PCR amplification and genotyping assays. Primer sequences for the VEGF polymorphisms were designed based on the Genbank sequences M63971 and AF024710. The sequences, as well as more detailed PCR conditions, are available on request.

PCRs were carried out in a total reaction volume of $20 \mu \mathrm{l}$ using $20 \mathrm{ng}$ of genomic DNA with the following amplification protocol: $95^{\circ} \mathrm{C}$ for $2.5 \mathrm{~min}$ followed by 35 cycles at $95^{\circ} \mathrm{C}$ for $30 \mathrm{sec}, 60^{\circ} \mathrm{C}$ for $30 \mathrm{sec}$ and $72^{\circ} \mathrm{C}$ for $30 \mathrm{sec}$, with a final extension at $72^{\circ} \mathrm{C}$ for $5 \mathrm{~min}$.

$-2549 \mathrm{del} / \mathrm{ins} 18 \mathrm{bp}$ was genotyped by separation in a $3 \%$ NuSieve (Cambrex Bio Science Rockland Inc., Rockland, ME, USA)/1\% agarose gel, and bands were visualized by ethidium bromide staining and UV-light.

The SNPs -2578 C/A (rs699947), -1154 G/A (rs1570360), $-634 \mathrm{G} / \mathrm{C}(\mathrm{rs} 201963)$ and $+936 \mathrm{C} / \mathrm{T}$ (rs3025039) were geno- typed with the MegaBACE ${ }^{\mathrm{TM}} \mathrm{SNuPe}{ }^{\mathrm{TM}}$ Genotyping Kit (GE Healthcare, Buckinghamshire, UK) (primer sequences available on request) according to the manufacturer's recommendations.

Statistical analysis. The Hardy-Weinberg equilibrium of alleles was tested for each SNP to compare the observed genotype frequencies with the expected genotype frequencies among the control subjects.

Statistical analysis was performed with SPSS v15.0 (SPSS UK Ltd., Woking, UK) and EpiInfo v3.3.2 (Centers for Disease Control and Prevention, Atlanta, GA, USA). Odds ratios (OR) were calculated with corresponding Yates-corrected $\chi^{2}$ tests and $95 \%$ confidence intervals (CI). P-values $<0.05$ (twotailed) were considered statistically significant.

Haplotype and linkage disequilibrium analysis was performed with Haploview v3.32 (http://www.broad.mit.edu/mpg/ haploview), where Lewontin's standardized disequilibrium coefficient D' was derived for each SNP and diplotypes were derived with Phase v2.1 (23) and analyzed using SPSS.

Power calculations were performed with PS v2.1.31 (24) and based on the comparison of the genotypes containing the assumed risk allele hypothesized to contribute to higher levels of VEGF (Table I) and the genotype containing the assumed non-risk allele. An exception was VEGF $+936 \mathrm{C} / \mathrm{T}$, in which the TT genotype was found to be rare and combined with the heterozygous group. $+936 \mathrm{C} / \mathrm{T}$ was also excluded from the haplotype analysis due to its weak association with the promoter/5'-UTR SNPs and the relatively low frequency of the $\mathrm{T}$ allele.

Relative mRNA concentrations were expressed as the means \pm standard error (SE). The student's t-test was used to compare the mean values of the different groups.

\section{Results}

VEGF mRNA expression. VEGF-A mRNA expression levels were upregulated 2.1-fold in colorectal tumors compared to normal colonic mucosa $(\mathrm{p}<0.01)$ and slightly elevated in tumors with the C-G-G haplotype (-2578 C/A, -1154 G/A and $-634 \mathrm{G} / \mathrm{C}$, respectively) compared to levels in individuals not harboring this haplotype, although this difference did not reach statistical significance (1.7-fold upregulation) $(\mathrm{p}=0.09)$. No association regarding any of the other genotypes or haplotypes and VEGF-A mRNA levels was evident (data not shown), and no association was observed between VEGF mRNA levels and clinicopathological characteristics (data not shown).

Haplotype analysis and genotype/haplotype frequencies among patients and controls. Lewontin's standardized disequilibrium coefficient (D') was calculated as a measure for linkage disequilibrium (LD) between the studied SNPs in the VEGF gene (Fig. 1). Promoter and 5'-UTR polymorphisms (-2578 C/A, -2549 del/ins 18 bp, -1154 G/A and -634 G/C) were found to be in tight or even complete LD (Fig. 1). -2578 $\mathrm{C} / \mathrm{A}$ was therefore used as a marker in the haplotype analysis. On the other hand, the $+936 \mathrm{C} / \mathrm{T}$ polymorphism was only weakly associated with the others, which is consistent with previous reports $(6,8)$. Hence, it was excluded from further haplotype analysis. 


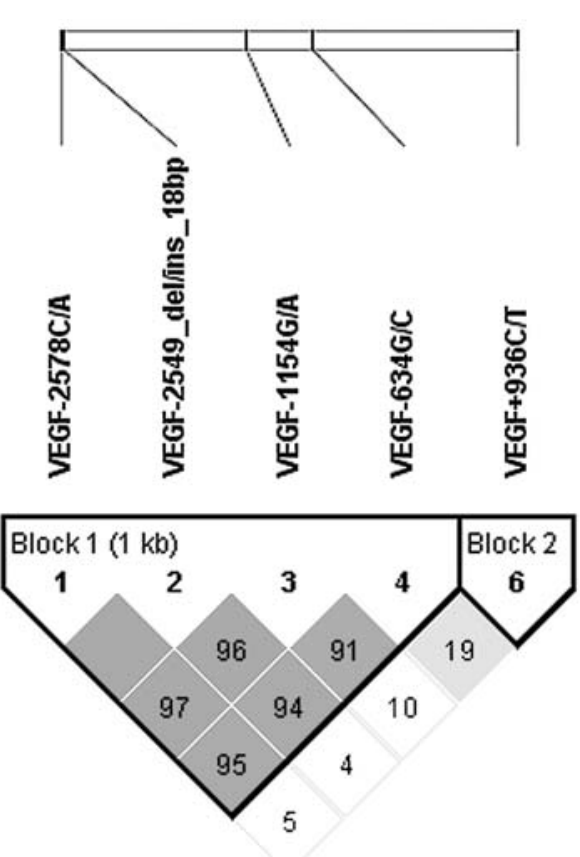

Figure 1. The linkage disequilibrium (LD) map derived from Lewontin's standardized disequilibrium coefficient $\left(D^{\prime}\right)$ of the five single nucleotide polymorphisms studied across the VEGF gene. Shown is the LD between the five studied polymorphisms. The SNPs and insertion in the promoter and 5'-UTR were in tight LD ( $\left|D^{\prime}\right|=0.91-1.00$, haplotype block 1$)$, but the +936 $\mathrm{C} / \mathrm{T}$ polymorphism was only weakly associated with the others $\left(\mathrm{ID}^{\prime} \mid=0.05\right.$ 0.19 , haplotype block 2). Given this, combined with the low frequency of the VEGF +936 TT genotype, haplotype analysis was restricted to haplotype block 1 (-2578 C/A, -1154 G/A and -634 G/C). -2578 C/A and -2549 del/ins 18 bp were confirmed to be in complete LD (6), and $-2578 \mathrm{C} / \mathrm{A}$ was used as a marker in the haplotype analysis.

The four most common haplotypes with frequencies $>1 \%$ were C-G-C, A-A-G, C-G-G and A-G-G (-2578 C/A, -2549 $\mathrm{del} / \mathrm{ins}$ and $-1154 \mathrm{G} / \mathrm{A}$, respectively). Haplotype frequencies are presented in Table I. No significant differences were observed when VEGF genotypes or haplotypes in the CRC cases and controls were compared (Table I), nor were any associations between the genotypes or haplotypes and the various clinical/pathological data studied disclosed (data not shown).

However, combining the $-2578 \mathrm{C}$ and $+936 \mathrm{~T}$ alleles revealed a small yet significant overrepresentation of this genotype combination in the $\mathrm{CRC}$ population $(\mathrm{OR}=1.6$; $95 \%$ CI, 1.3-1.6; $\mathrm{p}=0.01$ ).

In general, the allele and genotype distributions of the polymorphisms were in close agreement with previously published studies involving healthy Caucasians $(6,8)$.

Statistical power. The study had a statistical power of $\geq 81 \%$ to detect an $\mathrm{OR} \geq 1.9$ regarding all genotypes/ haplotypes on a two-sided significance level of $\alpha=0.05$ (data not shown).

\section{Discussion}

VEGF is a major regulator of angiogenesis and a highly polymorphic gene with several genotypes shown to alter gene expression. In previous studies, the $-2578 \mathrm{CC},-2549$ del/del, -1154 GG and -634 CC genotypes were often correlated with increased VEGF production $(3,5,7)$, while the +936 T allele was associated with lower VEGF plasma levels (4). However, reports in the literature are not in full agreement. Stevens et al (7) showed that several haplotypes containing the $-634 \mathrm{C}$ allele were associated with suppressed promoter activity in tumor cells.

VEGF plays a significant role in CRC progression (17-19), but the potential role of these SNPs in VEGF tumor expression and their importance in tumor growth, as well as their characteristics, have yet to be fully elucidated.

In the present study, VEGF mRNA was found to be upregulated in colorectal tumors compared to normal colonic mucosa (2.1-fold, $\mathrm{p}<0.01)$, in agreement with previous studies $(20,25)$. However, in the present samples, none of the polymorphisms/haplotypes investigated discriminated between high vs. low VEGF-expressing tumors, although there was a tendency toward enhanced VEGF mRNA levels (1.7-fold; $\mathrm{p}=0.09$ ) among individuals harboring the $\mathrm{C}-\mathrm{G}-\mathrm{G}$ haplotype (-2578 C/A, -2549 del/ins and -1154 G/A) compared to those not harboring it. Previous studies investigating the relationship between VEGF SNPs and mRNA levels in CRC found no major associations $(25,26)$, which is in line with our results and implies that the influence of VEGF promoter SNPs on VEGF expression may be limited in colorectal tumors. In contrast, other studies on plasma levels and cell cultures have been published $(3,4,7)$, revealing a strong influence of these polymorphisms on VEGF promoter activity and gene expression. Thus, the importance of these SNPs appears to differ depending on the tissue and cell type investigated. Possibly, upstream regulatory pathways such as HIF-1 $\alpha$, MAPK or PI3K $(27,28)$, rather than variants in the regulatory regions of the VEGF gene, play a significant and more decisive role in regulating VEGF expression in colorectal cancer.

We also analyzed the correlation between the described VEGF polymorphisms (genotypes and combined haplotypes) and CRC susceptibility and clinicopathological characteristics in a sample population consisting of 302 CRC patients and 336 controls. A combination of the $-2578 \mathrm{C}$ and $+936 \mathrm{~T}$ alleles was slightly more common in CRC patients compared to control individuals $(\mathrm{OR}=1.6 ; \mathrm{p}=0.01)$, although the frequency of these combined alleles was relatively low (10.7 vs. $6.7 \%$ in the CRC and control group, respectively). Other studies, mostly involving a relatively small population sample, found different associations between the investigated SNPs and tumor development. Chae et al (29) found that the $-634 \mathrm{G} /$ +936 T combination was associated with a decreased susceptibility to $\mathrm{CRC}$ in a Korean population, which in part contradicts our findings. We chose to combine $+936 \mathrm{C} / \mathrm{T}$ with $-2578 \mathrm{C} / \mathrm{A}$ rather than $-634 \mathrm{G} / \mathrm{C}$. However, the latter two are in strong LD and located in the same haplotype block, and should therefore not contribute significantly to the different results.

With regard to the $+936 \mathrm{SNP}$, in a study by Chae et al the TT genotype was associated with a higher tumor grade, metastasis and increased levels of the CA19-9 tumor marker in serum. However, Hofmann et al (30) was not able to verify these results, and found no association between the -2578 $\mathrm{C} / \mathrm{A},-634 \mathrm{G} / \mathrm{C}$ and $+936 \mathrm{C} / \mathrm{T}$ polymorphisms and $\mathrm{CRC}$ in an Austrian population, genetically more comparable to ours. 
Table I. Association of VEGF genotypes and haplotypes with colorectal cancer.

\begin{tabular}{|c|c|c|c|c|}
\hline & $\begin{array}{c}\text { Cases }(\mathrm{n}=302) \\
\text { no. }(\%)\end{array}$ & $\begin{array}{c}\text { Controls }(\mathrm{n}=336) \\
\text { no. }(\%)\end{array}$ & OR $(95 \%$ CI $)$ & P-value \\
\hline \multicolumn{5}{|l|}{ Genotypes } \\
\hline \multicolumn{5}{|c|}{$V E G F-2578 C / A$} \\
\hline $\mathrm{CC}^{\mathrm{a}}$ & $82(27.2)$ & $83(24.7)$ & 1 & \\
\hline $\mathrm{CA}$ & $150(47.5)$ & $181(53.9)$ & $1.19(0.81-1.76)$ & 0.41 \\
\hline AA & $70(22.2)$ & $72(21.4)$ & $1.02(0.63-1.63)$ & 0.96 \\
\hline $\mathrm{CA}+\mathrm{AA}$ & $232(79.2)$ & $253(75.3)$ & $1.14(0.78-1.65)$ & 0.54 \\
\hline \multicolumn{5}{|c|}{$V E G F-1154 G / A$} \\
\hline $\mathrm{GG}^{\mathrm{a}}$ & $138(46.6)$ & $156(47.0)$ & 1 & \\
\hline GA & $131(44.3)$ & $142(42.8)$ & $0.96(0.68-1.35)$ & 0.81 \\
\hline AA & $27 \quad(9.1)$ & $34(10.2)$ & $1.11(0.62-2.01)$ & 0.86 \\
\hline $\mathrm{GA}+\mathrm{AA}$ & $158(53.4)$ & $176(53.0)$ & $0.99(0.71-1.37)$ & 0.99 \\
\hline \multicolumn{5}{|c|}{$V E G F-634 G / C$} \\
\hline GG & 135 (44.7) & $167(49.7)$ & 1 & \\
\hline $\mathrm{GC}$ & $130(43.0)$ & $137(40.8)$ & $0.85(0.60-1.20)$ & 0.39 \\
\hline $\mathrm{CC}^{\mathrm{a}}$ & $37(12.7)$ & $32 \quad(9.5)$ & $0.70(0.40-1.22)$ & 0.23 \\
\hline $\mathrm{GC}+\mathrm{CC}$ & $167(55.7)$ & $169(50.3)$ & $0.82(0.59-1.13)$ & 0.24 \\
\hline \multicolumn{5}{|c|}{$V E G F+936 C / T$} \\
\hline $\mathrm{CC}^{\mathrm{a}}$ & $197(65.2)$ & $239(71.1)$ & 1 & \\
\hline $\mathrm{CT}$ & $91(30.1)$ & $88(26.2)$ & $0.80(0.55-1.15)$ & 0.23 \\
\hline TT & 14 (4.6) & $9 \quad(2.7)$ & $0.53(0.21-1.34)$ & 0.21 \\
\hline $\mathrm{CT}+\mathrm{TT}$ & 105 (34.7) & $97(28.9)$ & $0.76(0.54-1.08)$ & 0.13 \\
\hline \multicolumn{5}{|c|}{$\begin{array}{l}\text { Haplotypes }^{\mathrm{c}} \\
(-2578 \mathrm{C} / \mathrm{A},-1154 \mathrm{G} / \mathrm{A},-634 \mathrm{G} / \mathrm{C})\end{array}$} \\
\hline$A-A-G^{b}$ & $185(30.4)$ & $202(30.3)$ & 1 & \\
\hline C-G-C & $200(33.0)$ & $192(28.7)$ & $0.88(0.66-1.18)$ & 0.41 \\
\hline C-G-G & 114 (18.7) & $150(22.4)$ & $1.21(0.87-1.67)$ & 0.28 \\
\hline A-G-G & $102(16.8)$ & $114(17.1)$ & $1.02(0.72-1.45)$ & 0.96 \\
\hline \multirow{2}{*}{\multicolumn{5}{|c|}{$\begin{array}{l}\text { Haplotypes (frequencies) }{ }^{\mathrm{d}} \\
\text { (Case-control associations) }^{\text {Case }}\end{array}$}} \\
\hline & & & & \\
\hline $\mathrm{A}-\mathrm{A}-\mathrm{G}^{\mathrm{b}}$ & 0.30 & 0.30 & $1.01(0.79-1.29)$ & 0.95 \\
\hline C-G-C & 0.33 & 0.29 & $1.22(0.96-1.56)$ & 0.11 \\
\hline C-G-G & 0.19 & 0.22 & $0.80(0.60-1.06)$ & 0.12 \\
\hline A-G-G & 0.17 & 0.17 & $0.98(0.72-1.33)$ & 0.95 \\
\hline
\end{tabular}

${ }^{a}$ The genotypes hypothesized to be the most probable risk factors for colorectal cancer. ${ }^{\mathrm{b}} \mathrm{A}-\mathrm{A}-\mathrm{G}$ is the haplotype hypothesized to have the lowest expression, and was used as the reference group. ${ }^{\mathrm{c}}$ Comparison between the haplotypes with a frequency $>1 \%$ in the study population. Counts are based on the number of haplotypes. ${ }^{\mathrm{d} D a t a}$ derived from Haploview and the Yates-corrected $\chi^{2}$ test. Comparisons are between cases and controls for each haplotype. Counts are based on the number of haplotypes.

A recent study by Maltese et al (31) showed a significant association between three VEGF promoter polymorphisms [rs699947 (-2578 C/A), rs833061 (-460 T/C) and rs2010963 $(-634 \mathrm{G} / \mathrm{C})]$ and the development of $\mathrm{CRC}$ in an Italian population. They found an association between VEGF -460 T/C polymorphisms and two haplotypes, C-C-C and A-C-G (-2578 C/A, $-460 \mathrm{~T} / \mathrm{C}$ and $-634 \mathrm{G} / \mathrm{C})$, related to this variant and the risk of developing CRC. In our study, we included the SNP rs1570360 but not rs833061, since these SNPs are in tight LD and located in the same haplotype block, which is also supported by similar genotype frequencies found in the two control populations. The reasons for differences depending on population in the results obtained are still obscure. However, excepting chance associations, hypothetical factors include different genetic backgrounds, diet/lifestyles, and/or spectra of colorectal tumors (e.g., localization and pathological phenotype).

Importantly, the power of our study to detect an OR $\geq 1.9$ for any of the polymorphisms investigated in relation to CRC susceptibility was greater than $80 \%$, indicating that 
the negative results obtained were probably not due to the relatively small size of the study population.

In conclusion, we demonstrated that VEGF mRNA is upregulated in colorectal tumors compared to normal colonic mucosa, but not significantly influenced by individual SNPs in the regulatory regions of the VEGF gene. A small but significant association between the combined $-634 \mathrm{C}$ and +936 T alleles and CRC susceptibility was observed, but no other association was found between the studied SNPs (genotypes or haplotypes) and CRC susceptibility or progression in our Swedish population sample. We therefore suggest that other mechanisms are responsible for individual differences in VEGF expression and its contribution to tumor development and progression.

\section{Acknowledgements}

The authors thank Mats Fredrikson for his contribution to the statistical analysis and discussions. This study was supported by grants from the Swedish Cancer Foundation.

\section{References}

1. Stoeltzing O, Liu W, Reinmuth M, et al: Angiogenesis and antiangiogenic therapy of colon cancer liver metastasis. Ann Surg Oncol 10: 722-733, 2003.

2. Tischer E, Mitchell R, Hartman T, Silva M, Gospodarowicz D, Fiddes JC and Abraham JA: The human gene for vascular endothelial growth factor. Multiple protein forms are encoded through alternative exon splicing. J Biol Chem 266: 11947-11954, 1991.

3. Mohammadi M, Ollier WE and Hutchinson IV: A functional association study of VEGF gene promoter polymorphisms with VEGF expression by stimulated pbm cells. Hum Immunol 64: S125, 2003.

4. Renner W, Kotschan S, Hoffmann C, Obermayer-Pietsch B and Pilger E: A common $936 \mathrm{C} / \mathrm{T}$ mutation in the gene for vascular endothelial growth factor is associated with vascular endothelial growth factor plasma levels. J Vasc Res 37: 443-448, 2000.

5. Watson CJ, Webb N, Bottomley MJ and Brenchley P: Identification of polymorphisms within the vascular endothelial growth factor (VEGF) gene: correlation with variation in VEGF protein production. Cytokine 12: 1232-1235, 2000.

6. Brogan IJ, Khan N, Isaac K, Hutchinson JA, Pravica V and Hutchinson IV: Novel polymorphisms in the promoter and 5' UTR regions of the human vascular endothelial growth factor gene. Hum Immunol 60: 1245-1249, 1999.

7. Stevens A, Soden J, Brenchley PE, Ralph S and Ray DW Haplotype analysis of the polymorphic human vascular endothelial growth factor gene promoter. Cancer Res 63: 812-816, 2003.

8. Jin Q, Hemminki K, Enquist E, et al: Vascular endothelial growth factor polymorphisms in relation to breast cancer development and prognosis. Clin Cancer Res 11: 3647-3653, 2005.

9. Sfar S, Hassen E, Saad H, Mosbah F and Chouchane L: Association of VEGF genetic polymorphisms with prostate carcinoma risk and clinical outcome. Cytokine 35: 21-28, 2006.

10. Koukourakis MI, Papazoglou D, Giatromanolaki A, Bougioukas G, Maltezos E and Sivridis E: VEGF gene sequence variation defines VEGF gene expression status and angiogenic activity in non-small lung cancer. Lung Cancer 46: 293-298, 2004.

11. Howell WM, Bateman AC, Turner SJ, Collins A and Theaker JM: Influence of vascular endothelial growth factor single nucleotide polymorphisms on tumor development in cutaneous malignant melanoma. Genes Immun 3: 229-232, 2002.
12. Butt C, Lim S, Greenwood CM and Rahman P: VEGF, FGF1, FGF2 and EGF gene polymorphisms and psoriatic arthritis. BMC Muscoloskelet Disord 8: 1, 2007.

13. Han SW, Kim GW, Seo JS, Kim SJ, Sa KH, Park JY, et al: VEGF gene polymorphisms and susceptibility to rheumatoid arthrithis. Rheumatology 43: 1173-1179, 2004.

14. Medford AR, Keen LJ, Bidwell JL and Millar AB: Vascular endothelial growth factor gene polymorphisms and acute respiratory distress syndrome. Thorax 60: 244-248, 2005.

15. Nam EJ, Han SW, Kim SU, Cho JH, Sa KH, Lee WK, et al: Association of vascular endothelial growth factor polymorphisms with Behcet disease in a Korean population. Hum Immunol 66: 1068-1073, 2005

16. Parkin DM, Bray F, Ferlay J and Pisani P: Global cancer statistics. CA Cancer J Clin 55: 74-108, 2005.

17. Nakamura M, Abe Y and Tokunaga T: Pathological significance of vascular endothelial growth factor $\mathrm{A}$ isoform expression in human cancer. Pathol Int 52: 331-339, 2002.

18. Hanrahan V, Currie MJ, Gunningham SP, et al: The angiogenic switch for vascular endothelial growth factor (VEGF)-A, VEGF-B, VEGF-C and VEGF-D in the adenomacarcinoma sequence during colorectal cancer progression. J Pathol 200: 183-194, 2003.

19. George ML, Tutton MG, Janssen F, et al: VEGF-A, VEGF-C and VEGF-D in colorectal cancer progression. Neoplasia 3: 420-427, 2001.

20. Garcia V, Garcia JM, Silva J, Pena C, Dominguez G, Lorenzo Y, et al: Levels of VEGF-A mRNA in plasma from patients with colorectal carcinoma as possible surrogate marker of angiogenesis. J Cancer Res Clin Oncol 134: 1165-1171, 2008.

21. Longo R and Gasparini G: Anti-VEGF therapy: the search for clinical biomarkers. Expert Rev Mol Diagn 8: 301-314, 2008.

22. Dimberg J, Hugander A, Sirsjo A and Soderkvist P: Enhanced expression of cyclooxygenase-2 and nuclear beta-catenin are related to mutations in the APC gene in human colorectal cancer. Anticancer Res 21: 911-915, 2001.

23. Stephens M, Smith N and Donnelly P: A new statistical method for haplotype reconstruction from population genotype data. Am J Hum Gen 73: 1162-1169, 2001.

24. Dupont WD and Plummer WD Jr: Power and sample size calculations: a review and computer program. Control Clin Trials 11: 116-128, 1990.

25. Yamamori M, Sakaeda T, Nakamura T, et al: Association of VEGF genotype with mRNA level in colorectal adenocarcinomas. Biochem Biophys Res Commun 325: 144-150, 2004.

26. Cacev T, Loncar B, Seiwerth S, Spaventi S and Kapitanovic S: Vascular endothelial growth factor polymorphisms -1154 G/A and $-460 \mathrm{C} / \mathrm{T}$ are not associated with VEGF mRNA expression and susceptibility to sporadic colon cancer. DNA Cell Biol 27: 569-574, 2008.

27. Forsythe JA, Jiang BH, Iyer NV, Agani F, Leung SW, Koos RD and Semenza GL: Activation of vascular endothelial growth factor gene transcription by hypoxia-inducible factor 1 . Mol Cell Biol 16: 4604-4613, 1996.

28. Barr LF, Campbell SE, Diette GB, Gabrielson EW, Kim S, Shim $\mathrm{H}$ and Dang CV: c-Myc suppresses the tumorigenicity of lung cancer cells and down-regulates vascular endothelial growth factor expression. Cancer Res 60: 143-149, 2000.

29. Chae YS, Kim JG, Sohn SK, Cho YY, Ahn BM, Moon JH, et al: Association of vascular endothelial growth factor gene polymorphisms with susceptibility and clinicopathologic characteristics of colorectal cancer. J Korean Med Sci 23: 421-427, 2008.

30. Hofmann G, Langsenlehner U, Renner W, Langsenlehner T, Yazdani-Biuki B and Clar H: Common single nucleotide polymorphisms in the vascular endothelial growth factor gene and colorectal cancer risk. J Cancer Res Clin Oncol 134: 591-595, 2008.

31. Maltese P, Canestrari E, Ruzzo A, Graziano AF, Loupakis F Tonini $\mathrm{G}$, et al: VEGF gene polymorphisms and susceptibility to colorectal cancer disease in Italian population. Int J Colorectal Dis: Epub ahead of print, 2008. 